\title{
The Need of Digital Competencies for the Industrial Internet of Things Manufacturing Era: A Case of Higher Students in Papua
}

\author{
Martha Betaubun * \\ Department of English Education, Faculty of Teacher Training and Education, Universitas Musamus, Merauke 99600, Indonesia
}

\begin{abstract}
The Industrial Internet of Things (IIoT) has become a substantial topic in line with the industrial revolution 4.0 era. Digital competency represents a vital role in the IIoT framework. This study seeks to explore the digital competencies used in supporting IIoT. Respondents involved in this study were 300 people who came from students from the engineering faculty at a university in Papua. The results showed that students had mastery of digital competence for IIoT at a moderate level. This research implies an urgent need for policies from universities to be able to design strategies to improve digital competency capabilities for IIoT.
\end{abstract}

Keywords: IIoT, Digital, Student, Papua

\section{Introduction}

Industry transformation has brought changes, especially in the manufacturing world. The industrial era two to three transformed the production process from focusing on water and steam to the use of mass power into the use of electricity [1]. Industrial era transformed in 2011 in the context of economic development in Germany known as industry 4.0 [2], which relies on the CyberPhysical System (CPS) in the industrial world to enable automation to improve industrial efficiency and also to encourage productivity without leaving the element of safety and transparency [3]. CPS cannot stand-alone and require a place to shelter to function in the industry 4.0 era. The Internet of Things (IoT) has become an essential foundation in the realization of Industry 4.0. Since the advent of IoT in 1999 [4], this has continued to support the creation of connections between devices owned by consumers and penetrated the trade and industry sectors [5]. The combination of the development of the industrial era and the presence of technological advances in the form of IoT brought specific changes to the industrial sector with the advent of the Industrial Internet of Things (IIoT).

Simply stated, the involvement of IoT in the industrial sector has led to a new concept in the form of IIoT. IIoT refers to the application of specific technologies in the form of IoT in the industrial sector with specific objectives in the industrial world $[3,6,7]$. The main components of IIoT include the relationship between industrial machine sensors and administrators who carry out local processing with the internet [8]. Internet in the industrial world has different characteristics from the internet owned by consumers.
The difference lies in how it is treated and how much value is created because the majority of the value of consumer/ social internet services is created from advertising [9]. The application of IoT in the industrial sector requires mastery of sufficient capabilities in the course of manufacturing activities. The presence of IIoT requires prospective workers, including students, to have digital competence that can be applied to the work field.

Students require mastery of digital competencies before entering the manufacturing industry. With digital competence, this ability will equip individuals to work effectively and efficiently to contribute to economic growth both regionally and globally [10]. Tight work competition requires individuals to have excellent skills in order to be explicitly applied to the manufacturing industry. Digital competence is inseparable from the adoption of ICT because almost all sectors from private companies to government agencies require these capabilities [11]. The role of education is seen to be essential to equip students with sufficient knowledge and practical abilities. Moreover, educational institutions are also agents that are expected to foster and facilitate individuals to have professional abilities that are following the needs of an ever-expanding industry [12].

In equipping students to have digital competencies, the education sector supports it with a 21 st-century learning framework. 21st-century learning requires students to have the ability to adapt to new types of information and knowledge independently [13]. Moreover, students must be equipped with a new paradigm that supports the development of abilities that are appropriate to the needs of society, especially the

\footnotetext{
* Corresponding author : marthabetaubun@unmus.ac.id
} 
manufacturing industry [14]. Exposure to the use of ICT in learning is urgent to be done by educators. With more exposure to the use of ICT, students are expected to have the ability to adapt it to be applied to different professional sectors [15].

Recent developments in the field of technology have brought the application of IIoT in the industrial field. Previous studies have generated the framework and taxonomy of IIoT [3]. In addition, the importance of controlling IoT in the manufacturing industry has also received attention from previous studies [16-19]. Besides, ICT skills also play an essential role for students to acquire before entering the industrial manufacture [20-22]. On the other hand, digital competence is also seen as a crucial aspect that needs to be mastered by students in order to adapt to industry requirements [12]. So far, studies related to digital competence in Indonesia are limited in education [23, 24], and there insufficient studies that investigate digital competence as an ability that needs to be mastered in the manufacturing world. Exploration related to digital capabilities possessed by students is vital in order to bring the suitability between industry needs and educational content.

This paper assesses the level of digital competence of students, specifically those who live in the province of Papua. With this study, it is expected to broaden understanding regarding the importance of digital competence, especially in Indonesia. The mastery of digital competencies during college is needed by students to equip them with abilities that are in line with industry requirements. The change towards digital society requires mastery of digital competencies to be able to survive. Especially without sufficient digital skills, students will continue to be left behind by changes in circumstances that occur, especially in the social and manufacturing fields in the 21 st century [25]. The results of the exploration of this study can be used as a reference by educational institutions in developing curricula that pay attention to the digital competencies of students and can improve them to match the needs of the industrial world.

Technically, IoT is a network of the internet that connects various physical objects in which the process of exchanging data internally and externally. IoT also has a dependency on the "world wide web" to help device connectivity through specific communication standard protocols [26]. Moreover, in summary, there are three linkages found in the IoT paradigm, which involve elements of the internet, objects, and semantics [27]. IoT integration with the world of industry occurs because of the demands of the development of onlinebased technology that is sustainable. IoT can sustain the sustainability of the industry with a variety of support in making connections wherever and whenever users want.

The application of IIoT requires mastering ICT in carrying out activities in the industrial world. Technological advancements require the adoption of ICT because technology will continue to develop in industry 4.0, which includes big data, system integration, IIoT, cloud to augmented reality [28]. Industry 4.0 brought a change in ICT that significantly transformed the types of jobs and capabilities of workers in the industrial sector [22]. Thus, students need to develop new competencies and abilities that are adapted to global developments, automation, and connectivity of the industrial sector [29]. Students must be equipped with the ability of ICT to make them adaptive and flexible in following the demands of the changing industrial world. As industrial 4.0 is running, it gives the possibility of the emergence of new types of jobs that are influenced by the needs of products and services by the market [30].

Digital competencies have an essential role in equipping ICT skills in students. In particular, previous studies have been carried out in the outside of Indonesia, finding that there is a correlation between digital competencies and motivation in the use of ICT [20]. Also, age and gender have a vital role in mastering digital abilities [25]. In addition, digital competencies function as part of operational capabilities that are a crucial key to academics in the following world developments. However, the previous study still focuses on subjects that are limited to educators who have not investigated aspects of learners.

Related to previous studies in Indonesia, the study, especially on the ability of digital competence of students, is still very limited. The previous study discusses digital abilities that focus on aspects of digital literacy with limited subjects, namely the teacher [31]. In addition, other studies explore limited digital competencies of pre-service teachers who focus on aspects of the native digital level. Furthermore, a limited study on workers in telecommunications companies has found a performance gap [32]. Specifically, there is no attempt to explore the digital competencies of students related to IIoT who occupy rural areas. This study tries to offer a new perspective of exploration conducted on students, especially in remote areas. This study will broaden the scope of variables in the form of gender and differences between ethnic Papuans and Non-Papuans. The results of this study will undoubtedly be different from previous studies in Indonesia, which took a limited subject only in western Indonesia. The results of this study are expected to provide new insight to policymakers to be able to act more to improve education in eastern Indonesia.

\section{Methodology}

This research is a quantitative descriptive study that aims to explore the level of digital competence possessed by students in one of the tertiary institutions in Papua. The respondents of this study were students from the engineering faculties, which consisted of civil, architectural, mechanical, electrical, informatics, and information majors. Data obtained by simple random sampling through online questionnaires using Google Form. The questionnaire link is distributed to students through the WhatsApp group, and the questionnaire filling time is done in two weeks on March 2-16, 2021. Based on the online questionnaire that has been distributed, a total of 200 responses have been collected. The online questionnaire distributed to respondents contained 22 questions that were adapted from several 
previous studies $[22,33]$. The questionnaire contains student demographic information in the form of gender, ethnicity, and devices owned by students and selfassessment of students' digital abilities. The demographic description of the respondents is described in Table 1. The questionnaire is presented in Indonesian to make it easier for respondents to fill out the questionnaire. On the other hand, the reliability and validity had been tested through the Smartpls application shows that the adapted questionnaire has a decent level of reliability $(>0.7)$ and validity $(>0.5)$ [34] as it is seen in Table 2 .

Table 1. Respondents Demographic Information

\begin{tabular}{|l|l|l|}
\hline Variables & N & \% \\
\hline Gender & & \\
\hline Male & 95 & 47.40 \\
\hline Female & 105 & 52.60 \\
\hline Ethnicity & & \\
\hline Non-Papua & 169 & 84.60 \\
\hline Papua & 31 & 15.40 \\
\hline Owned Devices & & \\
\hline Laptop & 115 & 57.70 \\
\hline Smartphone & 182 & 91 \\
\hline Tablet & 8 & 3.80 \\
\hline Basic Phone & 10 & 5.10 \\
\hline
\end{tabular}

Table 2. Reliability and Validity Measurement

\begin{tabular}{|l|l|l|}
\hline \multicolumn{1}{|c|}{ Variables } & $\begin{array}{c}\text { Cronbach's } \\
\text { Alpha }\end{array}$ & \multicolumn{1}{c|}{ AVE } \\
\hline Hardware Mastery & 0.762 & 0.591 \\
\hline Software Mastery & 0.901 & 0.773 \\
\hline Self-Competence & 0.823 & 0.681 \\
\hline Digital Security & 0.873 & 0.797 \\
\hline Digital Cooperation & 0.942 & 0.853 \\
\hline $\begin{array}{l}\text { Digital Development } \\
\text { Mastery }\end{array}$ & 0.727 & 0.639 \\
\hline
\end{tabular}

The data obtained is processed through various stages. Data from google form will be saved in the form of .xls. Then, responses from students will be processed using IBM SPSS 23 software to display the mean and standard deviation. The results of the processed data are then interpreted using the digital competency framework as follows $\bar{x}$ 0.0-1.7 (low competency), $\bar{x}$ 1.8-3.7 (moderate competency), $\overline{\mathrm{x}}$ 3.8-5.0 (high competency).

\section{Result and discussion}

The results of the self-assessment of students' digital competencies are shown in Table 3.1. Mastery of hardware is one variable of digital competencies. Hardware mastery is needed not only to recognize the device but also to recognize the features of the device. In general, the level of mastery of hardware is at a moderate level $(\overline{\mathrm{x}}=3)$. It was found that mastery over smartphone usage and the ability to connect devices with a WIFI network was the most accessible hardware mastery for respondents $(\overline{\mathrm{x}}=3.4)$. However, the mastery of digital devices globally is quite significantly different from other indicators of hardware mastery $(\overline{\mathrm{x}}=2.3)$.

Besides mastery of hardware, the ability to master the software is also an essential variable of digital competencies. There are differences in the level of mastery of hardware and software by respondents. The level of mastery of the software by respondents are, on average, exceeds the level of mastery of hardware $(\overline{\mathrm{x}}=$ 3.3). The aspect to note is that the respondents use of Microsoft Office $(x=3.9)$ more cleverly compared to other software mastery. In addition, the level of ability to download and upload is also at a moderate level $(\overline{\mathrm{x}}=$ 3.3). Moreover, on average, there is no significant difference between the mastery of using a browser and handling digital structures $(\overline{\mathrm{x}}=3)$.

In digital competencies, self-competence becomes a vital variable to master. Self-competence in this study is related to the ability to master the internet, crossplatform navigation, and self-troubleshooting. The ability of respondents' internet mastery is at a moderate level $(\overline{\mathrm{x}}=3.1)$. Besides that, the level of mastery of cross-platform navigation and self-troubleshooting has an equivalent level $(\overline{\mathrm{x}}=3.2)$.

The critical competency that needs to be mastered in other digital competencies is the awareness of data security. This knowledge is considered necessary because smooth connectivity will also pose various threats. In general, the level of respondents' digital security knowledge is the same as the level of selfcompetence $(\overline{\mathrm{x}}=3.2)$. Respondents have knowledge related to data privacy at a moderate level $(\overline{\mathrm{x}}=3.4)$. Meanwhile, respondents' knowledge related to the security of the device is at a level that is not much different from data privacy $(\overline{\mathrm{x}}=3.1)$.

Variable of digital collaboration is a component of digital competencies. Respondents are at a moderate level regarding their ability to work together using cloud computing, video-calls, and email usage $(\overline{\mathrm{x}}=3.1)$. The ability of respondents through social media to work together is at a moderate level $(\overline{\mathrm{x}}=2.9)$. It was found that the digital literacy level of respondents to read documents online was quite different from the ability to use cloud and email computing $(\overline{\mathrm{x}}=1.8)$. However, in general, the respondent's digital collaboration ability variable was quite low compared to other competencies variables $(\overline{\mathrm{x}}=2.7)$.

Digital competence is supported by the ability to follow technological developments. Students need to follow the development of technology to be able to improve their digital skills. On average, the ability of respondents to follow technological developments is at a moderate level $(\overline{\mathrm{x}}=3.4)$. Respondents have sufficient ability to follow technological developments $(\bar{x}=3.7)$. Also, respondents' mastery and knowledge related to new technology are at a moderate level $(\overline{\mathrm{x}}=3.2)$.

After elaborating on respondents' digital competency levels based on variables, this study 
expands the discussion by including other variables in the form of gender and ethnicity as it is seen in Table 3.2. In the gender variable, on average male has a better mastery of digital competence than female $(\bar{x}=3.4)$. Furthermore, regarding the average distribution of each variable, there is no significant difference between the digital capabilities of the gender. On the other hand, based on ethnicity variables, there are differences between Papuans and non-Papuans ethnic. The level of digital competencies of Papuan ethnic is lower compared to non-Papuans $(\overline{\mathrm{x}}=2.8)$. In general, in the ethnicity variable, the distribution of digital capabilities does not have a significant difference except in hardware $(\overline{\mathrm{x}}=2.1)$.

This present study is intended to determine the level of digital competence of students in Papua through selfassessment. On average, the level of digital ability of respondents is at a moderate level. The availability of digital equipment and internet access facilities is assumed to influence the level of digital competencies of respondents. Besides, aspects of motivation contribute to the mastery of ICT [20]. The circumstance to note is that human resources are also influential in the continuing industrial revolution. In addition, the industry needs adequate support from various sectors, especially from the digital sector. Industry 4.0 focuses on the extensive use of network systems and IoT [22]. IoT develops with the widespread application which covers cross sectors from transportation to health [17].

Moreover, IoT also has a role in handling big data, which will then be analyzed to make conclusions based on the dataset that has been collected [35]. Furthermore, the role of the administrator still plays a vital role in the operation of IoT. The automation element still requires human resources to override maintenance or troubleshooting actions. Students are expected to have sufficient digital competencies to be adaptive to the industry requirements.

Other findings from this study are also related to the previous study, which views gender as affecting the mastery of digital competencies. Gender factors influence digital competencies, which are the findings of this study correlated to several previous studies [36, 37]. On the other hand, ethnicity also contributes to the mastery of digital competencies following findings from previous studies [38, 39]. Gender and ethnicity should be a concern for educators in determining learning strategies in order to equip students before entering into the developing world of industry.

The development of the industrial world with the application of IIoT has transformed the old industrial pattern, which is very dependent on labor. The application of IIoT technology globally is not limited to production automation but can also present real-time information to users of the technology [40]. IIoT can realize the connectivity of various devices through software whose responsibility is to obtain data, monitor, analyze, and automatically react to specific patterns [18]. Furthermore, the framework of IIoT refers to several components, which include industry, connectivity, use, and devices, which include the placement, characteristics, and technology used [3]. Users occupy one crucial component in IIoT, which emphasizes the quality of human resources must have excellent digital competence to be able to play a role in IIoT.

\section{Conclusion}

Based on this study, the self-assessment of student digital competencies at one of the tertiary institutions is at a moderate level. Further policies should be made to respond to these findings to be able to enhance the digital competence of students in order to prepare professional skills before plunging into the industrial world that continues to transform through IIoT. Other findings from this study indicate that specific gender and ethnicity require more attention to be able to improve digital competence. Action through policy in the form of matriculation is needed to adequate the existing imbalances. Increased digital competence is expected to provide provisions for students under the requirements of professional competencies in the industrial sector.

\section{References}

1. Lukač, D. The fourth ICT-based industrial revolution" Industry 4.0"-HMI and the case of $C A E / C A D$ innovation with EPLAN P8. IEEE.

2. Rao, R., NEW-GEN INDUSTRIAL INTERNET OF THINGS AND ITS IMMINENT. (2019).

3. Boyes, H., et al., The industrial internet of things (IIoT): An analysis framework. Computers in industry, (2018). 101: p. 1-12.

4. Rose, K., S. Eldridge, and L. Chapin, The internet of things: an overview, Internet Society. 2015.

5. Darmois, E. and O. Elloumi, Introduction to M2M. M2M communications: a systems approach. John Wiley \& Sons, (2012).

6. Prihandoko, L.A., et al. English language competence for tourism sector in supporting socioeconomic development in Merauke: A Survey Study. IOP Publishing. (2019)

7. Tembang, Y., et al. Improving science learning outcomes in material changes in natural appearance. IOP Publishing, (2019).

8. Leber, J., General Electric's San Ramon Software Center Takes Shape MIT Technology Review. Available: Technologyreview. com, (2012).

9. Floyer, D., Defining and sizing the industrial Internet. Wikibon, Marlborough, MA, USA, 2013.

10. Ananiadou, K. and M. Claro, 21st century skills and competences for new millennium learners in OECD countries. (2009).

11. Colmenero, M.J.R. and R.C. Gutiérrez, Usos y competencias en TIC en los futuros maestros de educación infantil y primaria: hacia una alfabetización tecnológica real para docentes. Pixel-Bit. Revista de Medios y Educación, 2015(47): p. 23-39.

12. Casillas, S., et al. Evaluation of digital competence from a gender perspective.

13. Baş, G., M. Kubiatko, and A.M. Sünbül, Teachers' perceptions towards ICTs in teaching-learning 
process: Scale validity and reliability study. Computers in Human Behavior, (2016). 61: p. 176185.

14. Martix, S. and J. Hodson, Teaching with infographics: practising new digital competencies and visual literacies. (2014).

15. Yunis, M., A.-N. El-Kassar, and A. Tarhini, Impact of ICT-based innovations on organizational performance: The role of corporate entrepreneurship. Journal of Enterprise Information Management, (2017).

16. van Deursen, A.J.A.M., et al., Digital inequalities in the Internet of Things: differences in attitudes, material access, skills, and usage. Information, Communication \& Society, (2021). 24(2): p. 258276.

17. Sezer, O.B., E. Dogdu, and A.M. Ozbayoglu, Context-aware computing, learning, and big data in internet of things: a survey. IEEE Internet of Things Journal, (2017). 5(1): p. 1-27.

18. Ng, I.C.L. and S.Y.L. Wakenshaw, The Internetof-Things: Review and research directions. International Journal of Research in Marketing, (2017). 34(1): p. 3-21.

19. Prihandoko, L.A., The Interplay of Information Literacy, Learning Facility, Learning Achievement \& Motivation Toward Online Learning Experience During COVID-19 Crisis: PLS-SEM Approach. ENGLISH FRANCA: Academic Journal of English Language and Education, (2021). 5(1): p. 79-94.

20. Guillén-Gámez, F.D., et al., Analysis of teachers' pedagogical digital competence: Identification of factors predicting their acquisition. Technology, Knowledge and Learning, (2020): p. 1-18.

21. Nugraha, S. and L.A. Prihandoko. Preliminary Study of Digital Manufacturing Requirement for Kampus Merdeka Apprenticeship Program. IOP Publishing,(2021).

22. Motyl, B., et al., How will change the future engineers' skills in the Industry 4.0 framework? A questionnaire survey. Procedia manufacturing, (2017). 11: p. 1501-1509.

23. Sejati, A.P., et al. Digital native levels of Indonesia pre-service teachers. IOP Publishing.

24. Utami, D.R.F. and L. Latiana. Teachers' Perception of The Professional Competencies and Digital Media Use at Early Childhood Institution in Indonesia. Atlantis Press, (2018).

25. Guillén-Gámez, F.D., M.J. Mayorga-Fernández, and F.J. Álvarez-García, A study on the actual use of digital competence in the practicum of education degree. Technology, Knowledge and Learning, (2020). 25(3): p. 667-684.

26. Santucci, G. and S. Lange. Internet of things in (2020): a roadmap for the future.

27. Atzori, L., Iera A.-Morabito G. The Internet of Things: A survey, (2010).

28. Rüßmann, M., et al., Industry 4.0: The future of productivity and growth in manufacturing industries. Boston Consulting Group, (2015). 9(1): p. 54-89.

29. Wallner, T., et al. Academic Education 4.0.
30. Lorenz, M., et al., Man and machine in industry 4.0: How will technology transform the industrial workforce through 2025. The Boston Consulting Group, (2015). 2.

31. Rizal, R., W. Setiawan, and D. Rusdiana. Digital literacy of preservice science teacher. IOP Publishing, (2019).

32. Aisyah, S.N. and A.I. Susanty, Measurement Gap of Competency in Preparing Employees for Digital Company (A Case Study of Telecommunication Company in Indonesia). (2017).

33. Atoy Jr, M.B., et al., Linking digital literacy and online information searching strategies of Philippine university students: The moderating role of mindfulness. Journal of Librarianship and Information Science, (2020). 52(4): p. 1015-1027.

34. Wong, K.K.-K., Partial least squares structural equation modeling (PLS-SEM) techniques using SmartPLS. Marketing Bulletin, (2013). 24(1): p. 132.

35. Zaslavsky, A., C. Perera, and D. Georgakopoulos, Sensing as a service and big data. arXiv preprint arXiv:1301.0159, (2013).

36. Balta, N. and M. Duran, Attitudes of students and teachers towards the use of interactive whiteboards in elementary and secondary school classrooms. Turkish Online Journal of Educational Technology-TOJET, (2015). 14(2): p. 15-21.

37. İlkan, M., et al., The role of information and communication technology (ICT) in tourism education: A case study of higher education students. (2017).

38. Esteve-Mon, F., M. Llopis, and J. Adell-Segura, Digital competence and computational thinking of student teachers. International Journal of Emerging Technologies in Learning (IJET), (2020). 15(2): p. 29-41.

39. Heemskerk, I., et al., Inclusiveness and ICT in education: a focus on gender, ethnicity and social class. Journal of computer assisted learning, (2005). 21(1): p. 1-16.

40. Kaufmann, T., Geschäftsmodelle in Industrie 4.0 und dem Internet der Dinge: der Weg vom Anspruch in die Wirklichkeit. (2015): SpringerVerlag. 